\title{
Vital Capacity Induction with Sevoflurane in Children Results in Less Incidence of Withdrawal after Rocuronium than Tidal Volume Induction
}

Department of Anesthesiology and Pain Medicine, Seoul National University Bundang Hospital, Seoul National University College of Medicine, Seoul, Korea

Yun-Ok Park, M.D., Yang-Hyun Kim, M.D., Jin-Hee Kim, M.D., and Ah-Young Oh, M.D.

Background: The Vital capacity technique is known to have some advantages over the tidal volume technique during inhalation induction of anesthesia. The aim of this study was to compare the incidence of withdrawal movement associated with the intravenous administration of rocuronium $0.3 \mathrm{mg} / \mathrm{kg}$ in children during inhalation induction with sevoflurane using the tidal volume and vital capacity techniques.

Methods: We randomly assigned 130 patients (aged 5-12 years) to either tidal volume (group T) or vital capacity (group V) groups for inhalation induction with sevoflurane. Rocuronium $0.3 \mathrm{mg} / \mathrm{kg}$ was administrated after loss of the eyelash reflex. The time to loss of the eyelash reflex was recorded and adverse events during induction were documented. The patient's response to rocuronium injection was graded using a four-point scale.

Results: No significant differences were observed between the groups with respect to age, weight, and gender. The time to loss of the eyelash reflex was more rapid in group $\mathrm{V}$ than in group $\mathrm{T}(\mathrm{P}<0.05)$. Excitatory movement developed more frequently in group $\mathrm{T}$, and no significant differences were found in the incidence of other adverse events between the groups. The incidence of withdrawal movement associated with the injection of rocuronium was significantly lower in group $\mathrm{V}$ compared to group $\mathrm{T}$ (30 vs. $60 \%$; $\mathrm{P}<0.05$ ).

Conclusions: Inhalation induction with sevoflurane using the vital capacity technique decreased the incidence of withdrawal movement during the injection of rocuronium compared to the tidal volume technique. (Korean $\mathbf{J}$ Anesthesiol 2008; 54: S 1 $\sim 5)$

Key Words: anesthetic techniques, induction; anesthetics volatile, sevoflurane; neuromuscular block, rocuronium; pain, injection.

\section{INTRODUCTION}

Rocuronium is characterized by a rapid onset of action with an intermediate duration and is frequently used in pediatric patients. However, pain on injection of rocuronium is common and has been reported in 50 to $80 \%$ of adult patients. ${ }^{1)}$ The incidence of withdrawal movement in pediatric patients was even more frequent at 83 to $84 \%{ }^{2,3)}$ Numerous methods have been suggested to decrease the pain associated with rocuronium injection during intravenous (IV) induction. ${ }^{2-7)}$

Inhalation induction with sevoflurane is commonly used

Received : August 14, 2007

Corresponding to : Ah-Young Oh, Department of Anesthesiology and Pain Medicine, Seoul National University Bundang Hospital, 300, Gumidong, Bundang-gu, Seongnam 463-707, Korea. Tel: 82-31-787-7506, Fax: 82-31-787-4063, E-mail: oay1@snubh.org method especially in children. We experienced that withdrawal movements associated with injection of rocuronium were less frequently developed during inhalation induction with sevoflurane compared with IV induction with thiopental in children. However, there are no reports, as far as we know, about the incidence of withdrawal movement during inhalation induction of anesthesia.

In this randomized study, we evaluated and compared the incidence of withdrawal movement associated with rocuronium injection during inhalation induction with sevoflurane in children according to the two induction technique: tidal volume and vital capacity.

\section{MATERIALS AND METHODS}

The study was approved by our institutional review board, 
and informed parental consent was obtained for all patients. Using computer-generated numbers, 130 children, 5-12 years of age, ASA physical status I or II, undergoing general anesthesia were randomly assigned to the tidal volume (group $\mathrm{T}$ ) or vital capacity (group V) groups. Following randomization, the study design was open. Children with contraindications to inhalation induction of anesthesia (gastroesophageal reflux, myopathy or familial history of malignant hyperthermia), with neurological disease, and those who had received analgesics or sedatives within the previous $24 \mathrm{~h}$ were excluded from the study.

On the day of surgery, one of the investigators told the children in group $\mathrm{V}$ how to perform vital capacity breathing. Each child was instructed to breathe in as deeply as they could, hold their breath for as long as possible, and breathes out slowly, at which time a face mask (without a circuit) was applied to the face tightly. They were allowed to practice with the mask alone until they could perform the maneuver correctly. $\left.{ }^{89}\right)$ In group $\mathrm{T}$, they were instructed to maintain normal breathing. A venous cannula was placed at least $30 \mathrm{~min}$ before inducing anesthesia in a separate reception area in the operating room. A 22-gauge (20 gauge for patients $\geq 7$ years old) IV catheter was placed on the dorsum of the hand. Free flow of Ringer's lactate was confirmed by allowing the administration of $\geq 20 \mathrm{ml}$ by gravity.

Sedative premedication was not given. Monitoring consisted of noninvasive blood pressure, percutaneous oxygen saturation $\left(\mathrm{SpO}_{2}\right)$, and inspired and end-tidal sevoflurane and carbon dioxide measurements (Capnomac, Ultima (tm); Datex-Engstrom Division, Helsinki, Finland). The end-tidal sevoflurane concentrations were recorded at the time of injection of rocuronium. Anesthesia was administered via an unscented face mask and pediatric tubing on the regular adult circle system of an anesthesia machine (Aestiva 5(tm); Datex-Ohmeda, Madison, WI, USA) for all patients. The circuit was primed with $8 \%$ sevoflurane (Tec 6 Plus, Madison, WI, USA) in $4 \mathrm{~L} / \mathrm{min}$ nitrous oxide/2 L/min oxygen fresh gas flow for $3 \mathrm{~min}$. At the end of 3 min, the mask was applied to the patient's face tightly at the end of exhalation. In group $\mathrm{V}$, the patients were asked to breathe in as deeply as they could, hold their breath for as long as possible, and breathe out slowly. A successful vital capacity breath was defined as a completion of these three steps and breath holding was lasted at least 10s. Extra vital capacity breaths were taken. They were informed that they could breathe normally if they could no longer breath-holding.
The patients in group $\mathrm{T}$ were told to continue breathing normally from the face mask. Loss of the eyelash reflex was assessed by gently brushing the lashes of one eyelid with a finger every $5 \mathrm{~s}$ after the induction of anesthesia began. Immediately after the eyelash reflex had been lost, the inspired sevoflurane concentration was decreased to $4 \%$ and the fresh gas flow to $1 \mathrm{~L} / \mathrm{min}$ nitrous oxide $1 \mathrm{~L} / \mathrm{min}$ oxygen and assisted ventilation was started as gently as possible trying not to stimulate the children. Rocuronium $0.3 \mathrm{mg} / \mathrm{kg}$ without dilution (10 $\mathrm{mg} / \mathrm{ml}$ ) was injected over $5 \mathrm{sec}$. During the study period, the flow of the IV fluid was maintained at a rate of $5-7 \mathrm{ml} / \mathrm{min}$. The time from application of the facemask to loss of the eyelash reflex and duration of administration of sevoflurane before rocuronium injection were recorded. Adverse events occurring during the inhalation induction were noted (coughing, excitatory movement, laryngospasm, breath-holding). ${ }^{10)}$ After the rocuronium was injected, the anesthesiologist graded the patient's response as follows: $1=$ no response, $2=$ movement at the wrist only, $3=$ movement/withdrawal involving the arm only (elbow/shoulder), 4 = generalized response-withdrawal or movement in more than one extremity, cough, or breath-holding. After the withdrawal response was graded, the study was terminated and the anesthetic was continued at the discretion of the attending anesthesiologist.

\section{Statistical analysis}

The results were analyzed using SPSS for Windows, Version 12.0 (SPSS Inc., Chicago, IL). Based on an estimated incidence of approximately $80 \%$ of patients experiencing pain on injection of rocuronium, the sample size required to detect a $50 \%$ reduction at the 5\% level of significance and a power of $80 \%$ was 50 patients per group. Since the vital capacity technique is reported to fail in up to $20 \%$ of children, ${ }^{8,11)} 65$ children were enrolled in each group.

The patient characteristics were compared using the unpaired Student's t-test. The frequency with which any response (wrist movement or more) occurred was compared between the groups using the chi-square test or Fisher's exact test as appropriate. Two groups were compared on response level of withdrawal movements using a rank test (Mann-Whitney U-test). Data are expressed as the means $\pm \mathrm{SD}$, median (range) or number, as appropriate. Results were considered significant at $\mathrm{P}<0.05$. 
Table 1. Demographic Data

\begin{tabular}{lcc}
\hline & Group $\mathrm{T}(\mathrm{n}=62)$ & Group $\mathrm{V}(\mathrm{n}=56)$ \\
\hline Age $(\mathrm{yr})$ & $8.1(4.8-12.6)$ & $7.9(5.1-12.2)$ \\
Weight $(\mathrm{kg})$ & $29.2 \pm 9.2$ & $28.8 \pm 7.6$ \\
Sex ratio $(\mathrm{M} / \mathrm{F})$ & $33 / 29$ & $26 / 30$ \\
\hline
\end{tabular}

Data are mean $\pm \mathrm{SD}$, median (range) or number. No statistical difference was found between the groups. Group T: tidal volume group, Group V: vital capacity group.

Table 2. Induction Time and Adverse Events during Inhalation Induction of Anesthesia

\begin{tabular}{lcc}
\hline & Group T (n=62) & Group V ( $=56)$ \\
\hline $\begin{array}{l}\text { Time to loss of the } \\
\text { eyelash reflex (sec) }\end{array}$ & $43.2 \pm 7.6$ & $34.7 \pm 6.4^{*}$ \\
$\begin{array}{l}\text { Duration of administration } \\
\text { of sevoflurane before }\end{array}$ & $51.8 \pm 6.2$ & $44.0 \pm 7.0^{*}$ \\
rocuronium injection (sec) & & \\
Adverse events & $5(8 \%)$ & $6(11 \%)$ \\
$\quad$ Coughing & $10(16 \%)$ & $2(4 \%)^{*}$ \\
Excitatory movement & 0 & 0 \\
Laryngospasm & $1(2 \%)$ & 0 \\
Breath-holding &
\end{tabular}

Data are mean $\pm \mathrm{SD}$ or number (percentage). ${ }^{*} \mathrm{P}<0.05$ vs. group T. Group T: tidal volume group, Group V: vital capacity group.

\section{RESULTS}

The study recruited 130 patients. Seven patients in the vital capacity group did not complete the vital capacity induction properly. These seven children released their breaths and resumed respiration almost immediately after taking their breaths. Three patients in the tidal volume group (group $\mathrm{T}$ ) and two in the vital capacity group (group V) rejected the mask or the anesthetic because of its odor. These patients were excluded from the analysis.

No significant differences were detected between the groups with respect to age, weight, and gender (Table 1). The time from application of the face mask to loss of the eyelash reflex and duration of administration of sevoflurane before rocuronium injection were significantly shorter in group V. Excitatory movement during the induction of anesthesia was less frequent in group $\mathrm{V}$, and the incidence of other adverse events was not different between the groups (Table 2). The end-tidal sevoflurane concentrations at the time of injection of rocuronium were not significantly different between the groups (Table 3).
Table 3. End-tidal Concentration of Sevoflurane (\%) at Each Time Respect

\begin{tabular}{lcc}
\hline & $\begin{array}{l}\text { Group T } \\
(\mathrm{n}=62)\end{array}$ & $\begin{array}{l}\text { Group V } \\
(\mathrm{n}=56)\end{array}$ \\
\hline $\begin{array}{l}\text { Loss of eyelash reflex } \\
\text { Injection of rocuronium }\end{array}$ & $6.0 \pm 1.5$ & $5.9 \pm 1.2$ \\
\hline
\end{tabular}

Data are mean \pm SD. No statistical difference was found between groups. Group T: tidal volume group, Group V: vital capacity group.

Table 4. Incidence and Degree of Withdrawal Movements Associated with Rocuronium Injection

\begin{tabular}{llc}
\hline $\begin{array}{c}\text { Withdrawal movements } \\
\text { (a four point scale) }\end{array}$ & $\begin{array}{c}\text { Group T } \\
(\mathrm{n}=62)\end{array}$ & $\begin{array}{l}\text { Group V } \\
(\mathrm{n}=56)\end{array}$ \\
\hline 1 (no response) & $25(40 \%)$ & $39(70 \%)^{*}$ \\
2 (wrist) & $13(21 \%)$ & $11(20 \%)$ \\
3 (elbow/shoulder) & $10(16 \%)$ & $2(4 \%)^{*}$ \\
4 (generalized) & $14(23 \%)$ & $4(7 \%)^{*}$ \\
\hline
\end{tabular}

Data are number of patients (percentage). ${ }^{*} \mathrm{P}<0.05$ vs. group $\mathrm{T}$. Group T: tidal volume group, Group $\mathrm{V}$ : vital capacity group. Withdrawal movements: $1=$ no response, $2=$ movement at the wrist only, $3=$ movement/withdrawal involving arm only (elbow/shoulder), 4 = generalized response-withdrawal or movement in more than one extremity, cough, or breath-holding.

The incidence of overall withdrawal movement was $60 \%$ (37/62) in group $\mathrm{T}$ and $30 \%(17 / 56)$ in group $\mathrm{V}$. The incidence of generalized movement was $23 \%(14 / 62)$ in group $\mathrm{T}$ and $7 \%(4 / 56)$ in group $\mathrm{V}$ respectively. The incidence and severity of withdrawal movement was significantly lower in group $\mathrm{V}$ compared to group $\mathrm{T}(\mathrm{P}<0.05)$ (Table 4). The heart rate $(\mathrm{HR})$ and mean arterial pressure (MAP) after injection of rocuronium did not change significantly from baseline (before induction of anesthesia) values and also were not different between the groups.

\section{DISCUSSION}

This study demonstrated that when rocuronium was injected immediately after loss of consciousness during inhalation induction with sevoflurane, the incidence of withdrawal movement was significantly less frequent in vital capacity group compared to tidal volume group in children.

The inhalation inductions with sevoflurane are commonly used in children and are generally performed by tidal volume or vital capacity technique. Vital capacity technique requires a 
cooperative child who will exhale maximally and inhale a vital capacity breath and then hold that breath for as long as possible, which is not a simple sequence for a young child to follow. We enrolled children older than $5 \mathrm{yr}$ because it was our experience that these children could learn to perform vital capacity technique. Due to the complexity and possibility of failure of vital capacity technique, administering constant high inspired concentration of inhaled anesthetics from the start while the children breathe spontaneously may be used an alternative in clinical practice. ${ }^{12)}$ However, there are controversies in the induction characteristics and acceptability of both techniques. ${ }^{11,13,14)}$ Yurino and Kimura demonstrated in adult volunteers that time to loss of consciousness was shorter and the incidence of complications such as cough and involuntary movement during induction was lower in vital capacity group compared to tidal breathing group even though the end tidal concentration of sevoflurane was not different between the groups. ${ }^{11)}$ Lejus et al. have shown in children that end tidal sevoflurane concentration, bispectral index values, hemodynamic changes, and the incidence of respiratory events were similar in both groups but the vital capacity technique showed more rapid loss of eyelash reflex and preferred by the children compared to the tidal volume technique. ${ }^{13)}$ In our study, we found that vital capacity technique allowed more rapid injection of rocuronium based on the more rapid loss of eyelash reflex and less withdrawal movement compared to tidal volume technique. From our results, we can add additional proof that inhalation induction with vital capacity technique can not only achieve more rapid loss of consciousness but also more deep level of anesthesia at that point compared to tidal breathing technique. Theoretically, we can assume that by minimizing the amount of air in the lungs before inhalation of anesthetic and maximizing an inspiration breath, dilution of the inspired anesthetic gases with air is held to a minimum and the alveolar concentration of anesthetic is maximized with vital capacity breathing. However, we could find no significant differences in the end-tidal sevoflurane concentration between the two groups at the time of the injection of rocuronium. The time from the start of inhalation of sevoflurane to the injection of rocuronium was less than $1 \mathrm{~min}$ in both groups and both groups were primed and provided with $8 \%$ sevoflurane concentration. It is considered that a single vital capacity breath induced higher sevoflurane concentration at brain compared to tidal breathing which is evidenced by the difference in the incidence of withdrawal movement but the end tidal concentration of sevo- flurane could not reflect that subtle difference of anesthetic concentration at brain between the two groups.

The withdrawal movement after injection of rocuronium is known to be due to pain ${ }^{15)}$ and various methods have been investigated to reduce its incidence. Although the incidence and severity of withdrawal movement after injection of rocuronium is higher in children than in adults, ${ }^{2,3)}$ there are only limited number of studies in children. The methods tried in children are pretreatment with lidocaine, ${ }^{3)}$ ketamine, ${ }^{2)}$ and remifentanil ${ }^{16)}$ which reduced the incidence of withdrawal movement from 84 to $46 \%, 83$ to $27 \%$, and 94 to $23 \%$, respectively. In our results, the incidence of withdrawal movement was $30 \%$ in vital capacity group which is comparable to the incidence of previous reports with pretreatment in IV induction of anesthesia. However, in tidal volume group, the incidence of withdrawal movement was $60 \%$ which is too high to be clinically acceptable, and other methods to reduce the withdrawal movement, such as pretreatment drugs or more delayed injection of rocuronium, should be sought.

The intubating dose of rocuronium can be reduced in inhalation induction ${ }^{17,18)}$ and intubations can be performed even without a muscle relaxant. ${ }^{1920)}$ However, the use of an adequate dose of relaxant during inhalation induction can facilitate induction while reducing the complications of a high sevoflurane concentration. A small dose of rocuronium $(0.3 \mathrm{mg} / \mathrm{kg})$ was used in our study, which was smaller than the intubating dose used in previous studies in children during IV induction of anesthesia. However, we do not believe that the dose of rocuronium used affected the incidence of withdrawal movement because many studies of adult have reported a high incidence of severe burning pain with only precurarization dose of rocuronium. ${ }^{21-23)}$

In conclusion, vital capacity technique allows more rapid injection of rocuronium with lower incidence of withdrawal movement compared to tidal volume technique during inhalation induction with sevoflurane in children.

\section{REFERENCES}

1. Steegers MA, Robertson EN: Pain on injection of rocuronium bromide (letter). Anesth Analg 1996; 83: 203.

2. Liou JT, Hsu JC, Liu FC, Ching-Wah Sum D, Lui PW: Pretreatment with small-dose ketamine reduces withdrawal movements associated with injection of rocuronium in pediatric patients. Anesth Analg 2003; 97: 1294-7.

3. Shevchenko Y, Jocson JC, McRae VA, Stayer SA, Schwartz RE, 
Rehman M, et al: The use of lidocaine for preventing the withdrawal associated with the injection of rocuronium in children and adolescents. Anesth Analg 1999; 88: 746-8.

4. Turan A, Memis D, Karamanlioglu B, Sut N, Pamukcu Z: The prevention of pain from injection of rocuronium by magnesium sulphate, lignocaine, sodium bicarbonate and alfentanil. Anaesth Intens Care 2003; 31: 277-81.

5. Memis D, Turan A, Karamanlioglu B, Sut N, Pamukcu Z: The prevention of pain from injection of rocuronium by ondansetron, lidocaine, tramadol, and fentanyl. Anesth Analg 2002; 94: 1517-20.

6. Cheong KF, Wong WH. Pain on injection of rocuronium: influence of two doses of lignocaine pretreatment. Br J Anaesth 2000; 84: 106-7.

7. Reddy MS, Chen FG, Ng HP: Effect of ondansetron pretreatment on pain after rocuronium and propofol injection: a randomized, double-blind controlled comparison with lidocaine. Anaesthesia 2001; 56: 902-5.

8. Agnor RC, Sikich N, Lerman J: Single-breath vital capacity rapid inhalation induction in children: $8 \%$ sevoflurane versus $5 \%$ halothane. Anesthesiology 1998; 89: 379-84.

9. Ho KY, Chua WL, Lim SS, Ng AS: A comparison between singleand double-breath vital capacity inhalation induction with $8 \%$ sevoflurane in children. Paediatr Anaesth 2004; 14: 457-61.

10. Moore JK, Moore EW, Elliott RA, St Leger AS, Payne K, Kerr $\mathrm{J}$ : Propofol and halothane versus sevoflurane in paediatric day-case surgery: induction and recovery characteristics. Br J Anaesth 2003; 90: 461-6.

11. Yurino M, Kimura $\mathrm{H}$ : A comparison of vital capacity breath and tidal breathing techniques for induction of anaesthesia with high sevoflurane concentrations in nitrous oxide and oxygen. Anaesthesia 1995; 50: 308-11.

12. Baum VC, Yemen TA, Baum LD: Immediate $8 \%$ sevoflurane induction in children: a comparison with incremental sevoflurane and incremental halothane. Anesth Analg 1997; 85: 313-6.

13. Lejus C, Bazin V, Fernandez M, Nquyen JM, Radosevic A, Quere $\mathrm{MF}$, et al: Inhalation induction using sevoflurane in children: the single-breath vital capacity technique compared to the tidal volume technique. Anaesthesia 2006; 61: 535-40.
14. Baker CE, Smith I: Sevoflurane: a comparison between vital capacity and tidal breathing techniques for the induction of anaesthesia and laryngeal mask airway placement. Anaesthesia 1999; 54: 841-4.

15. Blunk JA, Seifert F, Schmelz M, Schmelz M, Reeh PW, Koppert $\mathrm{W}$ : Injection pain of rocuronium and vecuronium is evoked by direct activation of nociceptive nerve endings. Eur $\mathrm{J}$ Anaesthesiol 2003; 20: 245-53.

16. Kim JY, Kim JY, Kim YB, Kwak HJ: Pretreatment with remifentanil to prevent withdrawal after rocuronium in children. Br J Anaesth 2007; 98: 120-3.

17. Eikermann M, Hunkemoller I, Peine L, Armbruster W, Stegen B, Husing J, et al: Optimal rocuronium dose for intubation during inhalation induction with sevoflurane in children. $\mathrm{Br} \mathrm{J}$ Anaesth 2002; 89: 277-81.

18. Eikermann M, Rensing-Kohler K, Peters J: Probability of acceptable intubation conditions with low dose rocuronium during light sevoflurane anaesthesia in children. Acta Anaesthesiol Scand 2001; 45: 1036-41.

19. Inomata $\mathrm{S}$, Watanabe $\mathrm{S}$, Taguchi $\mathrm{M}$, Okada $\mathrm{M}$ : End-tidal sevoflurane concentration for tracheal intubation and minimum alveolar concentration in pediatric patients. Anesthesiololgy 1994; 80: 93-6.

20. Wappler F, Frings DP, Scholz J, Mann V, Koch C, Schulte am Esch J: Inhalation induction of anesthesia with $8 \%$ sevoflurane in children: conditions for endotracheal intubation and side-effects. Eur J Anaesthesiol 2003; 20: 548-54.

21. Tuncali B, Karci A, Tuncali BE, Mavioqlu O, Olquner CG, Ayhan $\mathrm{S}$, et al: Dilution of rocuronium to $0.5 \mathrm{mg} / \mathrm{mL}$ with $0.9 \% \mathrm{NaCl}$ eliminates the pain during intravenous injection in awake patients. Anesth Analg 2004; 99: 740-3.

22. Mencke T, Schreiber JU, Knoll H, Stracke C, Kleinschmidt S, Rensing $\mathrm{H}$, et al: Women report more pain on injection of a precurarization dose of rocuronium: a randomized, prospective, placebo-controlled trial. Acta Anaesthesiol Scand 2004; 48: 1245-8.

23. Chiarella AB, Jolly DT, Huston CM, Clanachan AS: Comparison of four strategies to reduce the pain associated with intravenous administration of rocuronium. Br J Anaesth 2003; 90: 377-9. 